\title{
Relative impact of COPD and comorbidities on generic health-related quality of life: a pooled analysis of the COSYCONET patient cohort and control subjects from the KORA and SHIP studies
}

Margarethe E. Wacker ${ }^{1 *}$, Rudolf A. Jörres ${ }^{2}$, Annika Karch ${ }^{3}$, Armin Koch ${ }^{3}$, Joachim Heinrich ${ }^{4}$, Stefan Karrasch ${ }^{2,4,5}$, Holger Schulz ${ }^{4}$, Annette Peters ${ }^{6}$, Sven Gläser ${ }^{7}$, Ralf Ewert ${ }^{7}$, Sebastian E. Baumeister ${ }^{8,9}$, Claus Vogelmeier ${ }^{10}$, Reiner Leidl ${ }^{1,11}$, Rolf Holle ${ }^{1}$ and for the COSYCONET study group

\begin{abstract}
Background: Health-related quality of life (HRQL) is an important patient-reported outcome measure used to describe the burden of chronic obstructive pulmonary disease (COPD) which is often accompanied by comorbid conditions.

Methods: Data from 2275 participants in the COPD cohort COSYCONET and from 4505 lung-healthy control subjects from the population-based KORA and SHIP studies were pooled. Main outcomes were the five dimensions of the generic EQ-5D-3 L questionnaire and two EQ-5D index scores using a tariff based on valuations from the general population and an experience-based tariff.

The association of COPD in GOLD grades 1-4 and of several comorbid conditions with the EQ-5D index scores was quantified by multiple linear regression models while adjusting for age, sex, education, body mass index (BMI), and smoking status.

Results: For all dimensions of the EQ-5D, the proportion of participants reporting problems was higher in the COPD group than in control subjects. COPD was associated with significant reductions in the EQ-5D index scores (-0.05 points for COPD grades 1/2, -0.09 for COPD grade 3, -0.18 for COPD grade 4 according to the preference-based utility tariff, all $p<0.0001$ ). Adjusted mean index scores were 0.89 in control subjects and $0.85,0.84,0.81$, and 0.72 in COPD grades $1-4$ according to the preference-based utility tariff and $0.76,0.71,0.68,0.64$, and 0.58 for control subjects and COPD grades 1-4 for the experience-based tariff respectively. Comorbidities had additive negative effects on the index scores; the effect sizes for comorbidities were comparable to or smaller than the effects of COPD grade 3. No statistically significant interactions between COPD and comorbidities were observed. Score differences between COPD patients and control subjects were most pronounced in younger age groups.

(Continued on next page)
\end{abstract}

\footnotetext{
* Correspondence: margarethe.wacker@helmholtz-muenchen.de

${ }^{1}$ Institute of Health Economics and Health Care Management, Helmholtz Zentrum München (GmbH) - German Research Center for Environmental Health, Comprehensive Pneumology Center Munich (CPC-M), Member of the German Center for Lung Research (DZL), Ingolstädter Landstr. 1, 85764 Neuherberg, Germany

Full list of author information is available at the end of the article
} 
(Continued from previous page)

Conclusions: Compared with control subjects, the considerable reduction of HRQL in patients with COPD was mainly due to respiratory limitations, but observed comorbidities added linearly to this effect. Younger COPD patients showed a greater loss of HRQL and may therefore be in specific need of comprehensive disease management.

Trial registration: NCT01245933

Keywords: COPD, Health-related quality of life, Utilities, Cohort study, Comorbidities

\section{Background}

Chronic obstructive pulmonary disease (COPD) is a highly prevalent disease and the fourth leading cause of death worldwide [1]. Therefore, COPD represents a major public health challenge [2]. Patients with COPD are affected to a varying extent by symptoms such as chronic cough, phlegm, dyspnea, and by acute exacerbations or episodes of acute worsening of the respiratory symptoms. These characteristics of COPD are associated with limitations in health-related quality of life (HRQL) [3-7]. Furthermore, HRQL in patients with COPD is also affected by comorbid conditions $[8,9]$ which are common due to advanced age, common risk factors such as smoking, and the presence of systemic inflammation $[10,11]$. Although several studies have demonstrated that comorbidities contribute to low HRQL in patients with COPD [9, 12-14], there is no evidence whether the effect of comorbid conditions on HRQL differs between patients with COPD and individuals without COPD.

Quantifying HRQL is important at the level of individual patients to assess their limitations, the course of disease over time, and the effects of medical interventions. However, HRQL assessment is also essential from a scientific perspective as patient-reported outcomes are important endpoints in clinical studies [15]. For health economic purposes, the effectiveness of health interventions is increasingly quantified using quality-adjusted life years (QALYs) that combine quality and quantity of life into one outcome. Health utilities as a preference-based valuation of health states and a measure of quality can be derived by some generic HRQL instruments such as the EQ-5D questionnaire. These utilities are crucial input parameters for economic COPD models estimating the cost-effectiveness of interventions. The use of national tariffs is recommended for the calculation of utilities whenever possible [16].

This study aims to quantify the impact of COPD on generic HRQL relative to lung-healthy individuals. Therefore, it compares the EQ-5D-3 L questionnaire between a large sample of COPD patients in all grades of airflow limitation and lung-healthy control subjects from two pooled population-based studies. The association of selected comorbid conditions with HRQL is analyzed in COPD patients and control subjects, which allows separation of the effect of COPD on HRQL from the effect of comorbidities. The underlying hypotheses were that 1)
HRQL in patients with COPD is impaired compared to control subjects, 2) HRQL deteriorates with increasing COPD grade and 3) comorbidities add to the effect of COPD on HRQL. Finally, national reference values on utilities in different COPD grades are reported that will be useful for economic evaluations of COPD.

\section{Methods}

\section{Study sample}

This is a cross-sectional analysis of three pooled data sources. Data from the baseline visit of the German national COPD cohort COSYCONET ("COPD and Systemic Consequences - Comorbidities Network") were compared with a lung-healthy control group from the population-based KORA ("Cooperative Health Research in the Augsburg Region") platform in Southern Germany and the SHIP ("Study of Health in Pomerania") cohorts in Northern Germany.

The COSYCONET cohort recruited 2741 subjects aged $\geq 40$ years with physician-diagnosed COPD between September 2010 and December 2013 through outpatient and inpatient healthcare providers, patient groups, and media campaigns and examined them in 31 study centers all over Germany. Exclusion criteria were previous lung transplantation or lung volume reduction surgery and lung malignancies. All participants had to be clinically stable at their examination visit defined as no moderate or severe exacerbations for at least 4 weeks at the time of enrollment. Details on the cohort have been published previously $[17,18]$.

The KORA platform comprises population-based health surveys with subsequent follow-up studies in the Augsburg region [19]. Two studies with lung function data were used: Within the KORA F4L study (2010) spirometry was performed in 1051 participants aged 4465 years. The KORA Age 1 study (2008) recruited participants from previous KORA studies aged 65-89 years and examined lung function by spirometry in a randomly selected sample of 1079 participants [20].

SHIP is a population-based, epidemiological project consisting of two independent cohorts, SHIP and SHIPTREND, selected from the counties of North- and East of Western Pomerania and the two cities of Greifswald and Stralsund [21]. Data from 1348 participants in the SHIP S2 study (2008-2012) and 2137 SHIP TREND 
participants (2008-2012) who were aged 40 years or older and performed spirometry were used.

Figure 1 provides a study flow chart. Pooled data from the KORA Age 1, KORA F4L, SHIP S2 and SHIP-TREND studies covered the general population in an age range of 40-90 years, which is comparable to the COPD cohort.

\section{Definition of COPD patients and lung-healthy control subjects}

In the COSYCONET COPD cohort, standardized spirometry was performed after bronchodilation [17]. In KORA and SHIP, spirometry was performed without bronchodilation. In all studies, COPD was defined as $\mathrm{FEV}_{1}$ / FVC $<0.7$ according to the GOLD criteria [2]. Participants with COPD according to this definition were excluded from the lung-healthy control groups taken from KORA and SHIP, as well as 92 KORA participants and 117 SHIP participants with a self-reported history of asthma.

COPD patients from the COSYCONET cohort were classified as grade 1 with $\mathrm{FEV}_{1} \%$ pred. $\geq 80$, grade 2 with $50 \leq \mathrm{FEV}_{1} \%$ pred. $<80$, grade 3 with $30 \leq \mathrm{FEV}_{1} \%$ pred. < 50, and grade 4 with $\mathrm{FEV}_{1} \%$ pred. $<30$. Predicted values were taken from the Global Lung Initiative (GLI) [22]. A total of 430 participants from the cohort reporting physician-diagnosed COPD but with $\mathrm{FEV}_{1} / \mathrm{FVC} \geq 0.7$ were excluded from this analysis, as well as 20 participants with incomplete or missing lung function data.

\section{HRQL assessment}

The main outcome of this analysis was the EQ-5D-3 L questionnaire as a generic HRQL instrument that assesses current health status without specifying a recall period. Its descriptive section covers five dimensions of health: mobility, self-care, usual activities, pain/discomfort, and anxiety/ depression, with three levels per item (1: no problems, 2: some problems, and 3: extreme problems). The second part of the questionnaire, the valuation section, comprises a Visual Analog Scale (VAS) for valuing health status on a rating scale from 0 (worst imaginable health state) to 100 (best imaginable health state). The VAS was not available in SHIP and KORA.

There are several tariffs for the scoring or valuation of 243 theoretically possible health states as described by the five dimensions of the EQ-5D-3 L questionnaire on a single metric (EQ-5D index) that ranges between 0 and 1 with higher values indicating better health. Countryspecific tariffs are preferred to reflect the valuation of health concerns by the specific population. A key aspect of tariffs is whether the valuations come from a representative sample of individuals that values hypothetical health states or from individuals who value their own, current

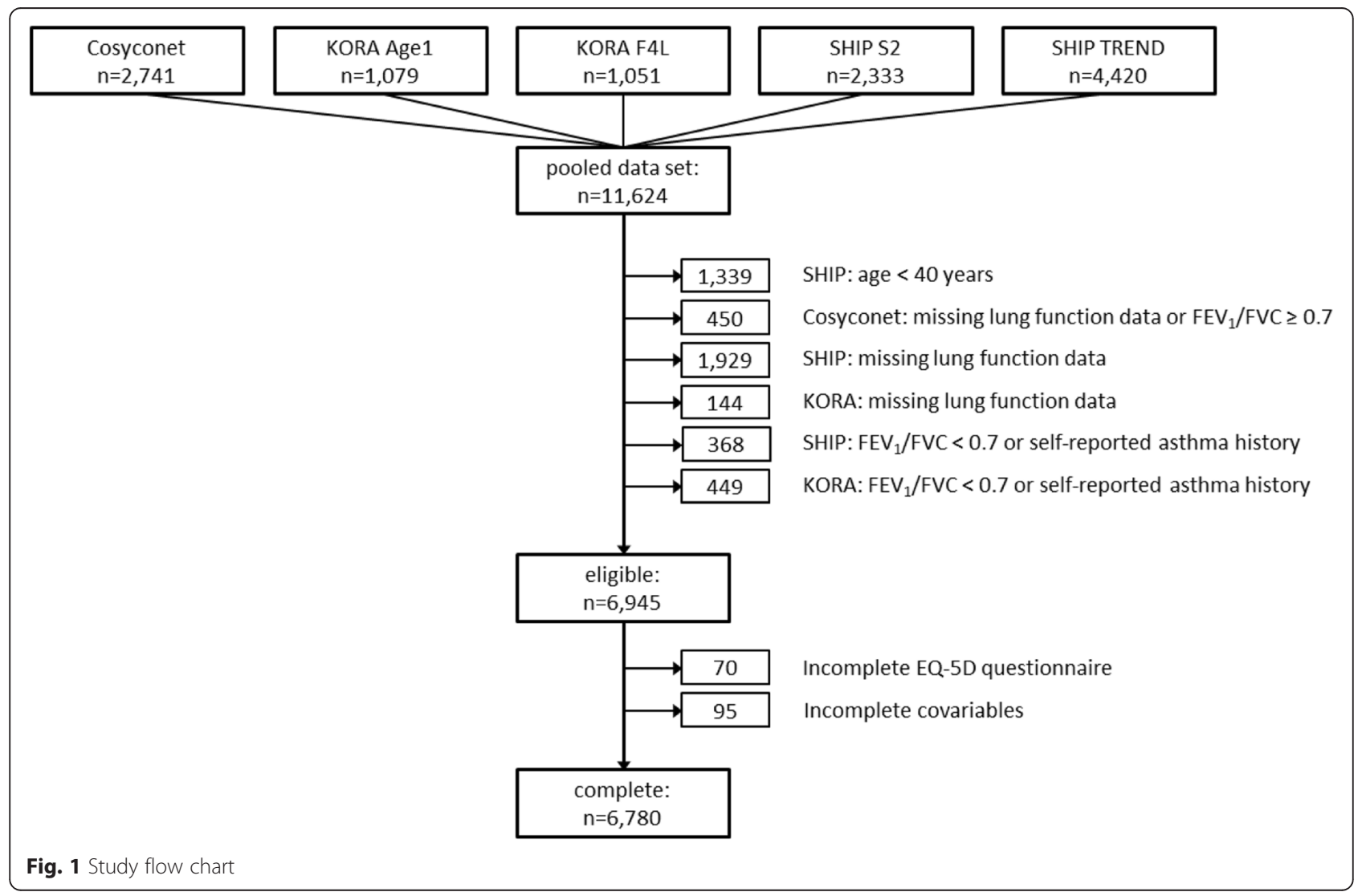


health state [23]. Traditional tariffs are based on the valuation of hypothetical or given health states (GHS) by the general population. They reflect preferences that individuals or society may have for any particular set of health outcomes in a situation of choice and can be interpreted as preference-based utilities. As a broad measure of benefits, utilities are essential for the quality-adjustment of life years and can be used in guiding resource allocation decisions. Alternative methods use the valuation of people who experience an actual health state, referred to as experienced health states (EHS), as these individuals have best insight regarding their health state.

In this analysis, we used the available German timetrade-off tariff of Greiner et al. [24], which is based on the valuation of GHS by a general population sample. The EQ$5 \mathrm{D}-3 \mathrm{~L}$ index resulting from this approach is subsequently referred to as the EQ-5D utility score. As the VAS was not available in all studies, we also used a recently developed German population EQ-5D index from Leidl et al. that is based on EHS [25]. This index uses the VAS for the valuation of health states of the EQ-5D-3 L and is therefore based on the valuation of health states by those who experience this health state instead of the general public. The EQ-5D-3 L index resulting from this additional approach is subsequently referred to as the EQ-5D valuation score.

Over all studies, 69 participants with missing or incomplete EQ-5D data were excluded.

\section{Covariates and comorbidities}

In all studies, participants' characteristics and data on comorbid conditions were assessed in standardized interviews and questionnaires. Participants' age and sex were considered as well as their level of school education (basic education $\leq 9$ years, secondary education 1011 years, higher education $>11$ years), body mass index (BMI, $\mathrm{kg} / \mathrm{m}^{2}$, determined from measured height and weight), and smoking status (smokers were defined as individuals who reported regular or occasional active cigarette smoking within the 4 weeks prior to the interview; former smokers were defined as individuals who reported regular or occasional active cigarette smoking in the past; never smokers were defined as individuals who reported no active cigarette smoking over lifetime). For four COSYCONET participants with missing information on smoking status, former smoking as the most frequent category was assumed. The presence of comorbidities was assessed by asking participants the question: "Has a physician ever diagnosed you with one of the following diseases?". Information on diabetes, cancer, stroke, myocardial infarction, and arthritis as frequent comorbid conditions was assessed in all studies in a comparable way and considered as comorbidities. Ninety-five observations with missing information regarding covariates were excluded from this analysis.

\section{Statistical analysis}

Characteristics of COPD patients in different grades and of control subjects were compared using analysis of variance (ANOVA) for continuous variables or for unadjusted means of the EQ-5D scores and $\mathrm{Chi}^{2}$-tests for categorical variables.

Multiple linear regression models (ordinary least squares, OLS) were conducted to assess the association between COPD in grades 1-4 and the EQ-5D index scores while adjusting for possible confounders.

To quantify the impact of comorbidities on HRQL, all analyses were performed with and without regression adjustment for comorbidities. This approach allows the division of the estimated effect of COPD into a part related to COPD itself and a part related to associated comorbidity. In the first step, the basic models included age group, sex, and level of school education as covariates. Extended models considered smoking status and BMI as possible risk factors and the selected comorbidities as additional covariables.

Interactions between COPD and comorbidities were analyzed by variable selection methods (PROC GLMSELECT with backward selection method) in order to examine nonadditive effects of comorbidities on HRQL. In addition, regression models were performed separately for COPD cases and control subjects to investigate possible differences in the effects of comorbidities in each group.

Although numerous studies have based the analysis of EQ-5D index scores on OLS [6, 26, 27], we additionally performed a sensitivity analysis with generalized linear regression models assuming a beta distribution with logit-link [28] in order to account for the skewed and censored distribution of the EQ-5D index scores.

Statistical analyses were performed using SAS software (SAS Institute Inc., Cary, NC, USA, version 9.3), and $p$-values of 0.05 or less were considered to be statistically significant.

\section{Results}

The characteristics of the 2275 participants in the COPD cohort and of 4505 lung-healthy control subjects are shown in Table 1. The COPD cohort had a higher mean age than the pooled control group (65.1 vs. 59.9 years, $p<0.0001)$, a higher proportion of males (61.1 vs. $49.3 \%, p<0.0001)$ and of participants with basic education (55.3 vs. $33.3 \%, p<0.0001$ ). The proportion of never smokers was lower in the COPD cohort than in control subjects $(6.5 \%$ vs. $42.8 \%, p<0.0001)$ as well as the mean BMI (26.7 vs. $\left.28.4 \mathrm{~kg} / \mathrm{m}^{2}, p<0.0001\right)$. Regarding comorbidities, stroke, cancer, and myocardial infarction were reported significantly more often in the COPD cohort than in the control group.

For the EQ-5D dimensions mobility, usual activities, and anxiety/depression, the proportion of participants 
Table 1 Characteristics of the study population

\begin{tabular}{|c|c|c|c|c|c|c|c|c|c|}
\hline & $\begin{array}{l}\text { KORA lung- healthy } \\
\text { control subjects }\end{array}$ & $\begin{array}{l}\text { SHIP lung-healthy } \\
\text { control subjects }\end{array}$ & Pooled control group & $\begin{array}{l}\text { COPD } \\
\text { grade } 1\end{array}$ & $\begin{array}{l}\text { COPD } \\
\text { grade } 2\end{array}$ & $\begin{array}{l}\text { COPD } \\
\text { grade } 3\end{array}$ & $\begin{array}{l}\text { COPD } \\
\text { grade } 4\end{array}$ & $\begin{array}{l}\text { Total COPD } \\
\text { cohort }\end{array}$ & $\begin{array}{l}p \text {-value (total cohort vs. } \\
\text { pooled control subjects) }\end{array}$ \\
\hline n & 1,506 & 2,999 & 4,505 & 204 & 954 & 869 & 248 & 2,275 & \\
\hline age (years) & $63.4(11.8)$ & $58.1(10.8)$ & $59.9(11.4)$ & $66.1(8.7)$ & $65.7(8.5)$ & $65.0(8.2)$ & $62.1(8.0)$ & $65.1(8.4)$ & $<0.0001^{\mathrm{a}}$ \\
\hline$\%$ age $<55$ years & $28.0(421)$ & $39.7(1,190)$ & $35.8(1,611)$ & $9.8(20)$ & $10.2(97)$ & $11.1(96)$ & $18.2(45)$ & $11.3(258)$ & $<0.0001^{\mathrm{b}}$ \\
\hline$\%$ age $55-64$ years & $28.0(421)$ & $28.8(863)$ & $28.5(1,284)$ & $27.5(56)$ & $31.9(304)$ & $34.4(299)$ & $43.2(107)$ & $33.7(766)$ & \\
\hline$\%$ age $65-74$ years & $21.4(322)$ & $24.5(734)$ & $23.4(1,056)$ & $48.0(98)$ & $44.6(425)$ & $44.0(382)$ & $31.9(79)$ & $43.3(984)$ & \\
\hline$\%$ age $>74$ years & $22.7(342)$ & $7.1(212)$ & $12.3(554)$ & $14.7(30)$ & $13.4(128)$ & $10.6(92)$ & $6.9(17)$ & $11.7(267)$ & \\
\hline$\%$ males & $48.1(724)$ & $49.9(1,496)$ & 49.3 & $60.3(123)$ & $60.6(578)$ & $61.1(531)$ & $64.1(159)$ & 61.1 & $<0.0001^{\mathrm{b}}$ \\
\hline $\mathrm{FEV}_{1}$ (liter) & $3.06(0.9)$ & $3.16(0.8)$ & $3.13(0.8)$ & $2.62(0.6)$ & $1.85(0.5)$ & $1.20(0.3)$ & $0.75(0.2)$ & $1.55(0.6)$ & $<0.0001^{\mathrm{a}}$ \\
\hline FVC (liter) & $3.92(1.1)$ & $3.96(1.0)$ & $3.95(1.1)$ & $4.11(0.9)$ & $3.31(0.9)$ & $2.67(0.8)$ & $2.05(0.6)$ & $3.00(1.0)$ & $<0.0001^{\mathrm{a}}$ \\
\hline $\begin{array}{l}\% \text { basic education } \\
\text { ( } \leq 9 \text { school years) }\end{array}$ & $56.2(847)$ & $21.8(854)$ & $33.3(1,501)$ & $48.0(98)$ & $52.1(497)$ & $60.0(521)$ & $57.7(143)$ & $55.3(1,259)$ & $<0.0001^{b}$ \\
\hline $\begin{array}{l}\text { \% secondary education } \\
\text { (10-11 school years) }\end{array}$ & $22.7(342)$ & $52.8(1,584)$ & $42.8(1,926)$ & $25.5(52)$ & $28.6(273)$ & $25.2(219)$ & $29.4(73)$ & $27.1(617)$ & \\
\hline $\begin{array}{l}\% \text { higher education } \\
\text { (>11 school years) }\end{array}$ & $21.1(317)$ & $25.4(761)$ & $23.9(1,078)$ & $26.5(54)$ & 19.3 (184) & $14.8(129)$ & $12.9(32)$ & 17.5 (399) & \\
\hline$\%$ smoker & $11.3(170)$ & $16.1(484)$ & $14.5(654)$ & $29.9(61)$ & $28.9(276)$ & $21.8(189)$ & $14.5(36)$ & $24.7(562)$ & $<0.0001^{b}$ \\
\hline \% former smoker & $39.2(590)$ & $44.4(1,332)$ & $42.7(1,922)$ & $62.8(128)$ & 63.7 (608) & $72.6(631)$ & 80.2 (199) & $68.8(1,566)$ & \\
\hline$\%$ never smoker & $49.5(746)$ & $39.5(1,183)$ & $42.8(1,929)$ & $7.4(15)$ & $7.3(70)$ & $5.6(49)$ & $5.2(13)$ & $6.5(147)$ & \\
\hline BMI $\left(\mathrm{kg} / \mathrm{m}^{2}\right)$ & $28.2(4.7)$ & $28.6(4.7)$ & $28.4(4.7)$ & $26.6(4.7)$ & $27.5(5.1)$ & $26.4(5.4)$ & $24.4(5.0)$ & $26.7(5.2)$ & $<0.0001^{\mathrm{a}}$ \\
\hline $\begin{array}{l}\% \text { normal weight } \\
(18.5 \leq \mathrm{BMl}<25)\end{array}$ & $24.4(368)$ & $22.7(681)$ & $23.3(1,049)$ & $36.8(75)$ & $32.5(310)$ & 38.4 (334) & $50.0(124)$ & 37.1 (843) & $<0.0001^{b}$ \\
\hline $\begin{array}{l}\% \text { overweight } \\
(25 \leq \mathrm{BMl}<30)\end{array}$ & $45.8(690)$ & $43.8(1,313)$ & $44.5(2,003)$ & $41.7(85)$ & 39.0 (372) & 36.1 (314) & $28.6(71)$ & $37.0(842)$ & \\
\hline$\%$ obese $(\mathrm{BMI} \geq 30$ ) & $29.6(445)$ & $33.4(1,003)$ & $32.1(1,448)$ & $20.1(41)$ & $27.0(258)$ & $20.9(182)$ & $11.7(29)$ & $22.4(510)$ & \\
\hline $\begin{array}{l}\text { \% underweight } \\
(\mathrm{BMl}<18.5)\end{array}$ & $0.2(3)$ & $0.1(2)$ & $0.1(5)$ & $1.5(3)$ & $1.5(14)$ & 4.5 (39) & $9.7(24)$ & $3.5(80)$ & \\
\hline$\%$ diabetes & $10.4(156)$ & 13.3 (399) & $12.3(555)$ & $10.3(21)$ & $13.3(127)$ & $12.8(111)$ & $11.3(28)$ & $12.6(287)$ & $0.73^{\mathrm{b}}$ \\
\hline$\%$ stroke & $4.1(61)$ & $2.5(75)$ & $3.0(136)$ & $3.9(8)$ & $4.3(41)$ & $4.8(42)$ & $2.4(6)$ & $4.3(97)$ & $0.008^{b}$ \\
\hline$\%$ myocardial infarction & $5.1(76)$ & $3.5(106)$ & $4.0(182)$ & $6.4(13)$ & $8.8(84)$ & $9.6(83)$ & $5.2(13)$ & $8.5(193)$ & $<0.0001^{\mathrm{b}}$ \\
\hline$\%$ cancer & $9.5(143)$ & $8.1(242)$ & $8.6(385)$ & $11.8(24)$ & $12.2(116)$ & $10.1(88)$ & $7.3(18)$ & $10.8(246)$ & $0.002^{b}$ \\
\hline$\%$ arthritis & $12.4(186)$ & $5.6(168)$ & $7.9(354)$ & $10.3(21)$ & $8.1(77)$ & $8.6(75)$ & $4.8(12)$ & $8.1(185)$ & $0.69^{b}$ \\
\hline EQ-5D utility score & $0.90(0.14)$ & $0.90(0.14)$ & $0.90(0.14)$ & $0.85(0.18)$ & $0.84(0.19)$ & $0.81(0.21)$ & $0.74(0.24)$ & $0.82(0.21)$ & $<0.0001^{\mathrm{a}}$ \\
\hline EQ-5D valuation score & $0.76(0.14)$ & $0.77(0.13)$ & $0.77(0.13)$ & $0.71(0.14)$ & $0.68(0.16)$ & $0.64(0.17)$ & $0.58(0.17)$ & $0.66(0.17)$ & $<0.0001^{\mathrm{a}}$ \\
\hline
\end{tabular}


reporting some or extreme problems was higher in the COPD groups than in control subjects and increased with higher COPD grade, as illustrated in Fig. 2. Especially for mobility and usual activities, a large proportion of COPD patients reported some or extreme problems, with up to $79 \%$ of participants in COPD grade 4 for usual activities. Regarding self-care, the proportion of participants reporting problems was comparable in COPD grade 1 and the control group, but steadily increased from grade 2 to grade 4 in the COPD group. As to pain and discomfort, a slightly higher proportion of COPD patients reported problems compared with control subjects, but within the COPD group, proportions were comparable with $70.6 \%$ in grade 1 and $64 \%$ in grade 3 .

Unadjusted mean EQ-5D utility and valuation scores for COPD grades 1-4 were lower than in the control group and decreased with increasing disease severity (Table 1).

Table 2 shows the results of the regression analyses. After adjusting for differences in age, sex, and education between groups, all COPD grades were associated with statistically significant reductions in both index scores. This reduction increased with higher disease grade. The effect estimates of COPD grades 1 and 2 were of a similar magnitude when considering the utility score and differed slightly when considering the valuation score. When controlling for smoking status, weight, and comorbidities in extended regression models, the negative effects of COPD grades 1-4 remained stable. All comorbid conditions had additional negative effects on the index scores; these effects were additive as all interaction terms between COPD grade and comorbid conditions were not statistically significant (results not shown). The effect sizes for comorbidities were comparable to or smaller than the effects of COPD grade 3, whereby a history of arthritis or stroke had the largest effects. The effect estimate of obesity was similar to the estimate of COPD grades 1 or 2 .

Table 3 shows the effect estimates of comorbid conditions, stratified for the COPD cohort and the control group. Most of the estimates were comparable in cases and control subjects. Figure 3 shows the adjusted mean index scores for all groups resulting from the basic regression model. Figure 4 illustrates adjusted mean index scores by age group. For both index scores, the gap between COPD patients and control subjects was more pronounced in younger than in older age groups.

The adjusted mean index scores based on a model assuming a beta-distribution with logit-link differed only marginally from those of the OLS models: a difference of -0.01 to +0.03 was observed for the means of the groups according to utility score and -0.01 to +0.01 according to the valuation score.

\section{Discussion}

Based on a large pooled data set, this study corroborates the significant reduction of generic $\mathrm{HRQL}$ in patients with COPD compared with lung-healthy control subjects. HRQL limitations increased with higher COPD disease grade. The coexistence of COPD with other diseases contributes to the overall burden by increasing HRQL limitations. Therefore, comorbid conditions are important to assess in the context of COPD management. The novel finding of this study was that the HRQL reductions were found to be primarily due to the lung disorder, whereas the effects of comorbidities were weaker and additive. Comorbid arthritis, stroke, and obesity had the largest additional effects on the HRQL index scores. However, significant interactions between COPD grades and comorbidities were not found. Notably, the HRQL gap between COPD patients and control subjects was larger in younger than in older age groups, which could be explained by a higher impact of dyspnea on HRQL [29]. As an individualized, patient-centered approach is postulated as the ideal care of COPD patients [30], younger patients with COPD may be an important target group for specific disease management.

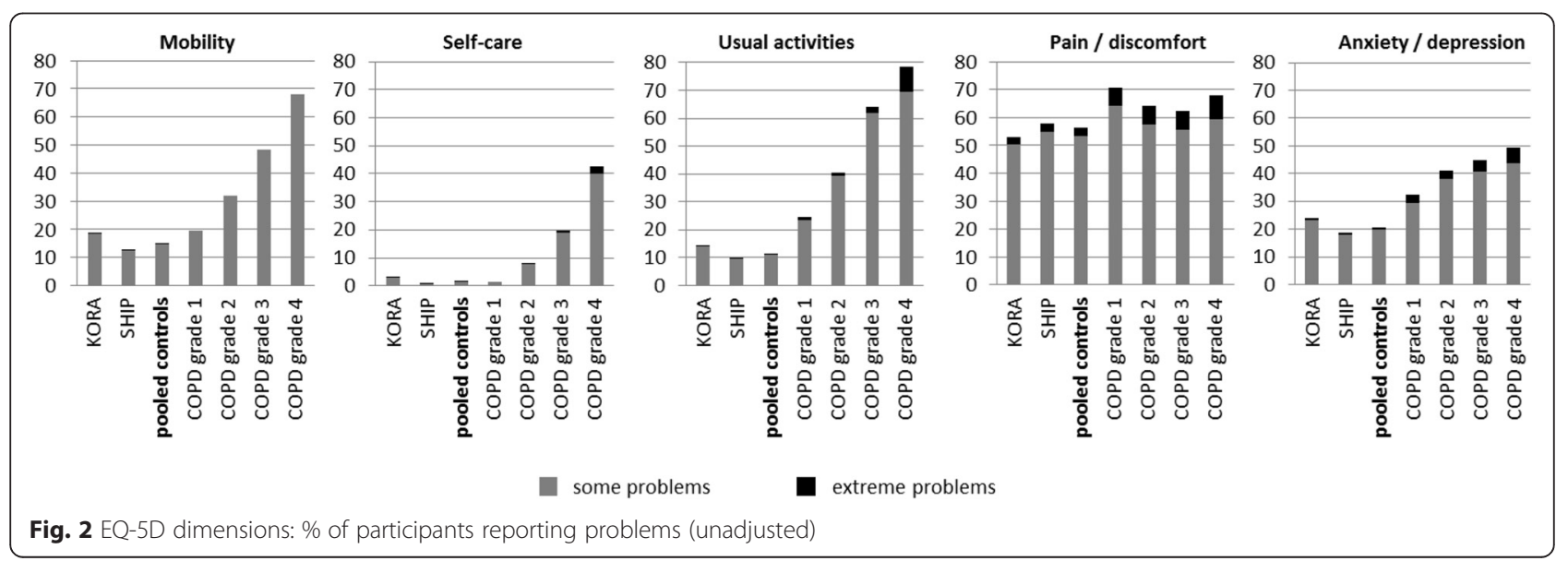


Table 2 Results of multiple linear regression models

\begin{tabular}{|c|c|c|c|c|c|}
\hline \multirow{2}{*}{ Covariate } & & \multicolumn{2}{|l|}{ EQ-5D utility score } & \multicolumn{2}{|l|}{ EQ-5D valuation score } \\
\hline & & Basic model & Extended model & Basic model & Extended model \\
\hline Intercept & & $\mathbf{0 . 9 1}[0.90$ to 0.92$]$ & $\mathbf{0 . 9 6}[0.94$ to 0.97$]$ & $\mathbf{0 . 7 8}[0.77$ to 0.79$]$ & $\mathbf{0 . 8 2}[0.81$ to 0.83$]$ \\
\hline \multirow[t]{5}{*}{ COPD } & no COPD & ref. & ref. & ref. & ref. \\
\hline & grade 1 & $\mathbf{- 0 . 0 4}[-0.06$ to -0.02$]$ & $\mathbf{- 0 . 0 5}[-0.07$ to -0.02$]$ & $\mathbf{- 0 . 0 5}[-0.07$ to -0.03$]$ & $\mathbf{- 0 . 0 6}[-0.07$ to -0.04$]$ \\
\hline & grade 2 & $-\mathbf{0 . 0 5}[-0.06$ to -0.04$]$ & $-0.05[-0.06$ to -0.04$]$ & $-\mathbf{0 . 0 8}[-0.09$ to -0.07$]$ & $\mathbf{- 0 . 0 8}[-0.09$ to -0.07$]$ \\
\hline & grade 3 & $\mathbf{- 0 . 0 8}[-0.09$ to -0.07$]$ & $\mathbf{- 0 . 0 9}[-0.10$ to -0.08$]$ & $-\mathbf{0 . 1 2}[-0.13$ to -0.11$]$ & $\mathbf{- 0 . 1 3}[-0.14$ to -0.12$]$ \\
\hline & grade 4 & $\mathbf{- 0 . 1 6}[-0.18$ to -0.14$]$ & $\mathbf{- 0 . 1 8}[-0.20$ to -0.15$]$ & $\mathbf{- 0 . 1 8}[-0.20$ to -0.16$]$ & $\mathbf{- 0 . 2 0}[-0.21$ to -0.18$]$ \\
\hline \multirow[t]{4}{*}{ Age (years) } & $<55$ & ref. & ref. & ref. & ref. \\
\hline & $55-64$ & $\mathbf{- 0 . 0 2}[-0.04$ to -0.01$]$ & $-0.01[-0.02$ to 0.00$]$ & $-\mathbf{0 . 0 3}[-0.04$ to -0.02$]$ & $\mathbf{- 0 . 0 2}[-0.02$ to -0.01$]$ \\
\hline & $65-74$ & $-\mathbf{0 . 0 2}[-0.03$ to -0.01$]$ & $-0.01[-0.02$ to 0.00$]$ & $-\mathbf{0 . 0 1}[-0.02$ to -0.00$]$ & $0.00[-0.01$ to 0.01$]$ \\
\hline & $>74$ & $-\mathbf{0 . 0 6}[-0.07$ to -0.04$]$ & $\mathbf{- 0 . 0 4}[-0.05$ to -0.02$]$ & $-\mathbf{0 . 0 6}[-0.07$ to -0.04$]$ & $\mathbf{- 0 . 0 4}[-0.05$ to -0.02$]$ \\
\hline \multirow[t]{2}{*}{ Sex } & male & ref. & ref. & ref. & ref. \\
\hline & female & $-\mathbf{0 . 0 1}[-0.02$ to -0.01$]$ & $-\mathbf{0 . 0 2}[-0.03$ to -0.01$]$ & $-\mathbf{0 . 0 2}[-0.03$ to -0.02$]$ & $-\mathbf{0 . 0 3}[-0.04$ to -0.02$]$ \\
\hline \multirow[t]{3}{*}{ Education } & basic ( $\leq 9$ school years) & ref. & ref. & ref. & ref. \\
\hline & secondary (10-11 school years) & $\mathbf{0 . 0 1}[0.01$ to 0.02$]$ & $0.01[-0.00$ to 0.02$]$ & $\mathbf{0 . 0 2}[0.01$ to 0.02$]$ & $\mathbf{0 . 0 1}[0.00$ to 0.02$]$ \\
\hline & higher (>11 school years) & $\mathbf{0 . 0 4}[0.03$ to 0.05$]$ & $\mathbf{0 . 0 3}[0.02$ to 0.04$]$ & $\mathbf{0 . 0 4}[0.03$ to 0.05$]$ & $0.03[0.02$ to 0.04$]$ \\
\hline \multirow[t]{3}{*}{ Smoking status } & never smoker & & ref. & & ref. \\
\hline & smoker & & $-0.02[-0.03$ to -0.00$]$ & & $-\mathbf{0 . 0 1}[-0.02$ to -0.00$]$ \\
\hline & former smoker & & $-0.01[-0.02$ to -0.00$]$ & & $-0.01[-0.01$ to 0.00$]$ \\
\hline \multirow[t]{4}{*}{ Weight } & normal weight $(18.5 \leq \mathrm{BMI}<25)$ & & ref. & & ref. \\
\hline & underweight (BMI < 18.5) & & $0.00[-0.03$ to 0.04$]$ & & $0.01[-0.02$ to 0.04$]$ \\
\hline & overweight $(25 \leq \mathrm{BMI}<30)$ & & $-\mathbf{0 . 0 2}[-0.03$ to -0.01$]$ & & $-\mathbf{0 . 0 2}[-0.02$ to -0.01$]$ \\
\hline & obese $(\mathrm{BMI} \geq 30)$ & & $-0.05[-0.06$ to -0.04$]$ & & $\mathbf{- 0 . 0 5}[-0.06$ to -0.04$]$ \\
\hline \multirow[t]{5}{*}{ Comorbidities } & diabetes & & $\mathbf{- 0 . 0 3}[-0.04$ to -0.02$]$ & & $\mathbf{- 0 . 0 2}[-0.04$ to -0.01$]$ \\
\hline & stroke & & $\mathbf{- 0 . 0 5}[-0.07$ to -0.03$]$ & & $\mathbf{- 0 . 0 5}[-0.07$ to -0.03$]$ \\
\hline & myocardial infarction & & $-\mathbf{0 . 0 4}[-0.05$ to -0.02$]$ & & $\mathbf{- 0 . 0 4}[-0.05$ to -0.02$]$ \\
\hline & cancer & & $-\mathbf{0 . 0 2}[-0.04$ to -0.01$]$ & & $-\mathbf{0 . 0 2}[-0.03$ to -0.01$]$ \\
\hline & arthritis & & $\mathbf{- 0 . 0 8}[-0.10$ to -0.07$]$ & & $\mathbf{- 0 . 0 8}[-0.09$ to -0.07$]$ \\
\hline
\end{tabular}

Estimates with $p<0.05$ are printed in bold

Table 3 Association of comorbid conditions with the EQ-5D index scores stratified for COPD cases and control subjects

\begin{tabular}{|c|c|c|c|c|}
\hline \multirow[b]{2}{*}{ Covariate } & \multicolumn{2}{|l|}{ EQ-5D utility score } & \multicolumn{2}{|l|}{ EQ-5D valuation score } \\
\hline & COPD cases & Control subjects & COPD cases & Control subjects \\
\hline Diabetes & $\mathbf{- 0 . 0 3}[-0.05$ to -0.00$]$ & $\mathbf{- 0 . 0 3}[-0.05$ to -0.02$]$ & $-0.01[-0.03$ to 0.01$]$ & $\mathbf{- 0 . 0 3}[-0.05$ to -0.02$]$ \\
\hline Stroke & $-0.04[-0.08$ to 0.00$]$ & $\mathbf{- 0 . 0 5}[-0.08$ to -0.03$]$ & $-0.03[-0.06$ to 0.00$]$ & $\mathbf{- 0 . 0 6}[-0.08$ to -0.04$]$ \\
\hline Myocardial infarction & $-\mathbf{0 . 0 5}[-0.08$ to -0.02$]$ & $-\mathbf{0 . 0 2}[-0.04$ to -0.00$]$ & $-\mathbf{0 . 0 5}[-0.07$ to -0.02$]$ & $\mathbf{- 0 . 0 3}[-0.05$ to -0.01$]$ \\
\hline Cancer & $\mathbf{- 0 . 0 3}[-0.05$ to -0.00$]$ & $\mathbf{- 0 . 0 2}[-0.03$ to -0.00$]$ & $-0.02[-0.04$ to 0.00$]$ & $\mathbf{- 0 . 0 3}[-0.04$ to -0.01$]$ \\
\hline Arthritis & $-\mathbf{0 . 0 9}[-0.12$ to -0.06$]$ & $\mathbf{- 0 . 0 8}[-0.09$ to -0.06$]$ & $\mathbf{- 0 . 0 7}[-0.10$ to -0.05$]$ & $\mathbf{- 0 . 0 8}[-0.09$ to -0.06$]$ \\
\hline Obesity (BMI $\geq 30$ ) & $\mathbf{- 0 . 0 6}[-0.08$ to -0.04$]$ & $\mathbf{- 0 . 0 4}[-0.05$ to -0.03$]$ & $\mathbf{- 0 . 0 4}[-0.06$ to -0.02$]$ & $\mathbf{- 0 . 0 4}[-0.05$ to -0.05$]$ \\
\hline
\end{tabular}

Estimates with $p<0.05$ are printed in bold 


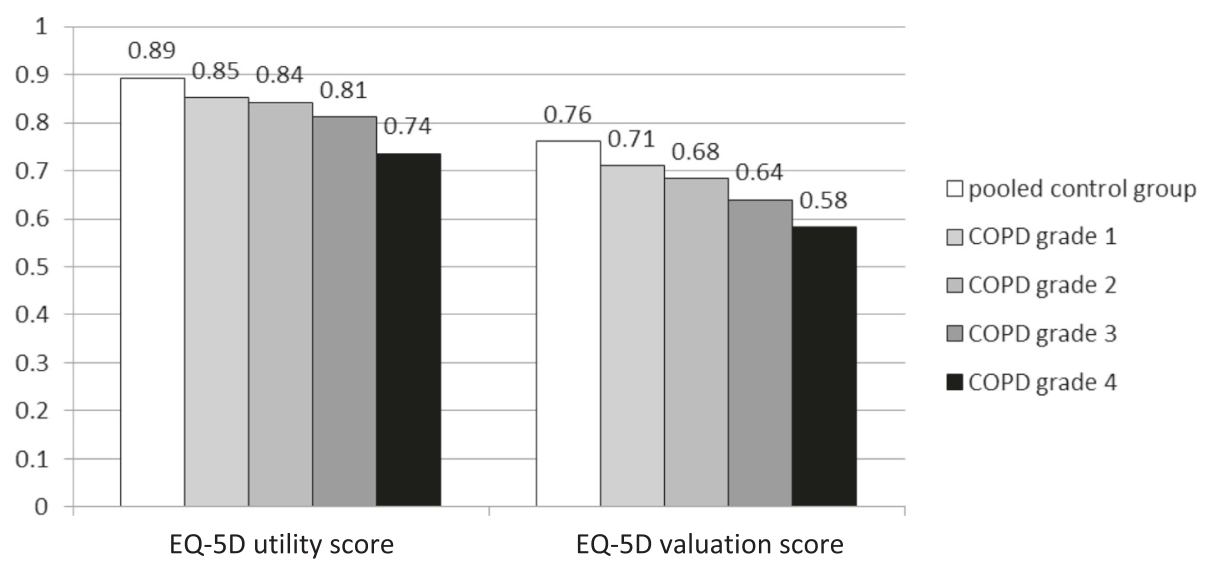

Fig. 3 Adjusted mean EQ-5D index scores. Models adjusted for age, sex, and education

The EQ-5D questionnaire is the most frequently used instrument for the calculation of health utilities and recommended by several reimbursement and academic authorities worldwide [31]. The validity, reliability, responsiveness, and discriminative properties of the EQ-5D in populations with COPD have been examined in several studies [5, 12, 32-34]. For the EQ-5D index scores used in this study, a minimal clinically important difference (MCID) has not yet been established. Based on studies using other scoring algorithms and in diseases other than COPD, it may range between 0.04 and $0.07[35,36]$. Therefore, the effects for
COPD grades observed in this study can be seen as clinically relevant.

This evidence corroborates previous studies that have already shown that increasing disease severity in COPD is associated with a reduction in EQ-5D utility and other generic or disease-specific HRQL scores [37-40]. However, it also expands previous evidence as there is a lack of studies considering the entire spectrum of disease grades and a comparison with control subjects $[6,12,39]$. The variation in published mean EQ-5D utility scores per COPD grade is considerable. Besides diverging underlying

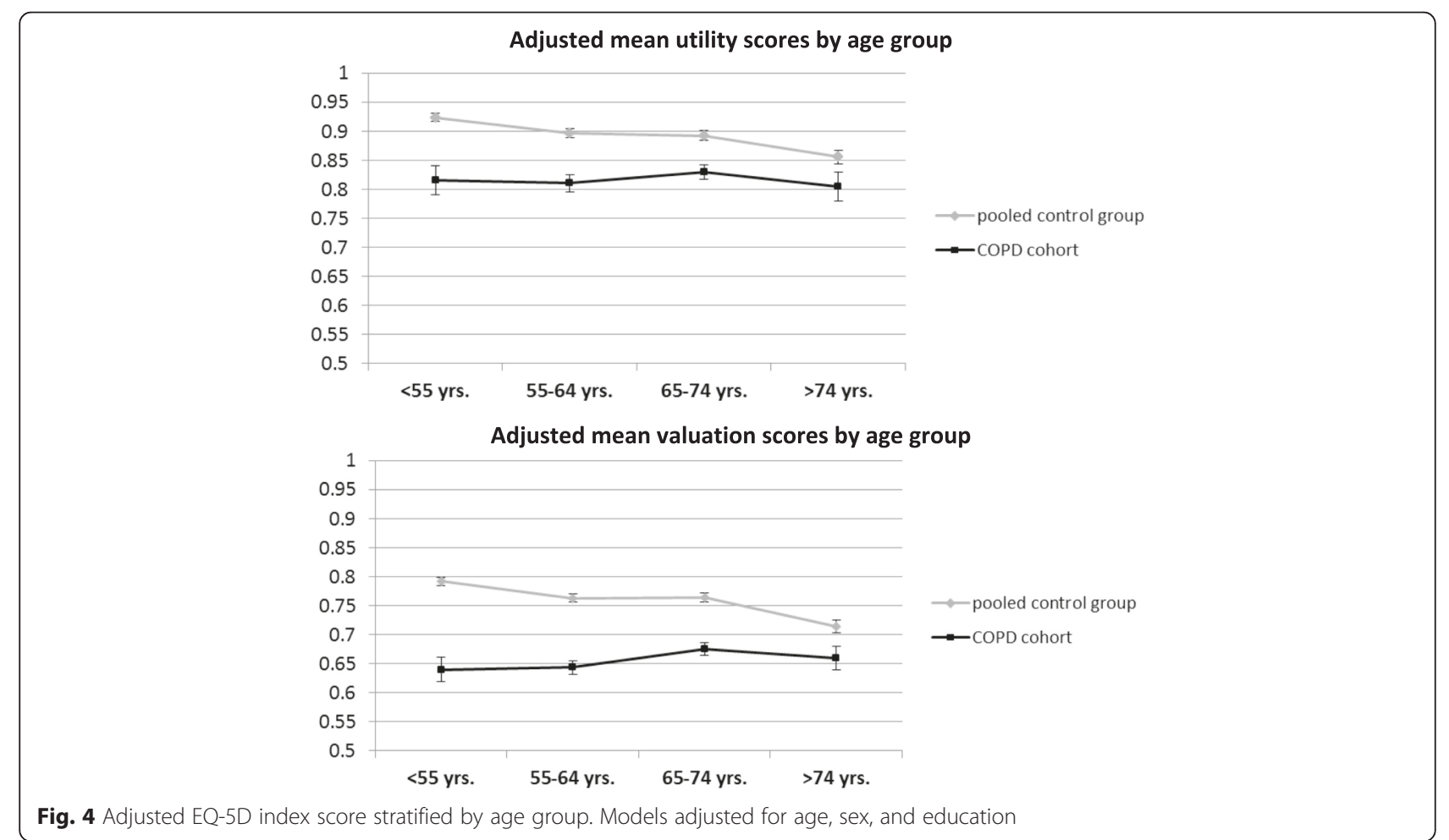


populations and definitions of COPD, the comparability of utilities with previous studies is hampered by differences in the scoring algorithms for the EQ-5D index. Differences between national EQ-5D tariffs have been shown to be substantial because of different methodological approaches, but also, to a minor degree, due to cultural differences in valuation. As these differences may influence the results of cost-utility analyses [16], national data on utilities are required for economic evaluations of COPD in Germany.

Einarson et al. reviewed 44 original articles that reported utilities related to COPD [41]. Irrespective of disease classification and utility instrument, methods or tariffs used, mean utilities were $0.83,0.77,0.71$, and 0.61 for GOLD grades 1-4 respectively. A review by Pickard et al. reported pooled mean utility scores based on a UK scoring algorithm of 0.74, 0.74, 0.69, and 0.61 for GOLD grades 1-4 [40]. Especially for early COPD grades the pooled mean utilities reported by Pickard et al. were lower than those found in this analysis and those reported by Einarson et al. Similar to Pickard et al., our study found comparable mean utilities for GOLD grades 1 and 2. This finding might be explained by possible ceiling effects of the EQ-5D questionnaire that limit the ability of this instrument to discriminate well between early COPD grades and have been described previously $[6,12,34]$. Nevertheless, the availability of control subjects enabled us to show a reduction in the EQ-5D index scores even in early disease grades.

There are only a few studies that have considered the effect of comorbidities on utilities in COPD patients. Most of them used the number of comorbid conditions or a weighted comorbidity index and found that a higher number of comorbidities is associated with a reduced utility $[12,14,34]$. By pooling data from patients with COPD and lung-healthy control subjects, we were able to separate the effect of COPD on HRQL from the effect of comorbidities. Our results show that the effects of comorbid conditions on the EQ-5D index scores were comparable between patients with COPD and lung-healthy control subjects and the size of comorbid effects was equal to or even smaller than the impact of COPD grade 3. Arthritis and stroke showed the highest effects and are therefore in need of special consideration. In line with our results, a previous study also did not find interactions or effect-modifications between COPD disease severity and comorbidity [12]. However, a comparison with control subjects was not considered.

The main strength of this study lies in the large sample size covering all COPD grades and the availability of control subjects from two population-based cohort studies. Individual data with standardized variable definitions could be pooled for this analysis.

Besides the established German EQ-5D utility tariff [24], an experience-based tariff for the valuation of health states into a single index score was additionally considered. Although national utility scores are needed for the calculation of QALYs and for cost-utility analyses in COPD, experience-based scores may be important for decision makers who want to base their decisions on experienced health states rather than on the valuation of these health states by the general population $[25,42]$. Whereas the utility tariff includes preferences on hypothetical health states, the valuation by the experience-based tariff refers to the health state of respondents, and valuation is done by VAS [25]. Both differences may contribute to the finding that valuations of the experience-based index are lower than those of the utility-tariff. As shown by another study of the COSYCONET cohort, preference-based utilities and patients' VAS valuations may also differ: Between grade 1 and 4, the utility-tariff indicated a difference of 0.13 while for patients' valuations, this was 0.22 [34], thus making the choice of valuation used in this study important to the results obtained.

This study is subject to methodologic limitations. First, the possibility of selection bias in all studies considered might have led to an over- or underestimation of the effect of COPD on the index scores. Although the results are based on data from a large COPD cohort that may be more easily generalized than those of clinical studies, as well as on a pooled control group from northern and southern Germany, it cannot be excluded that they are not fully representative for the entire German population. Second, the necessity of standardized and comparable covariates throughout all studies limited the range of variables that could have been taken into account. In particular, a comparison of the influence of further comorbidities was limited by the lack of comparable information. Therefore, the reductions in HRQL in COPD grades might be explained partly by the occurrence of other comorbidities that could not be compared between COPD cases and control subjects. This restriction could have led to an overestimation of the effects of COPD on index scores. Third, the comorbidities considered in our study may reflect historic conditions, such as infarction or cancer. The effects of recent comorbid events on HRQL might be more significant. Finally, the use of pre-bronchodilator spirometry data to exclude subjects with COPD from the control group might have led to a misclassification of subjects with asthma as COPD patients. Therefore, subjects with $\mathrm{FEV}_{1} / \mathrm{FVC} \geq 0.7$ and self-reported asthma were additionally excluded in order to create a lunghealthy control group. This approach might have led to an overestimation of the effects of COPD on HRQL scores because our control group might be healthier than a control group excluding COPD patients only.

\section{Conclusions}

Compared with control subjects, generic HRQL is considerably impaired in patients with COPD, even in early 
disease grades, and this was primarily caused by the lung disease and not the comorbidities. As this impairment is more pronounced in younger age groups, these patients are a particularly relevant target group for specific or comprehensive disease management.

\section{Abbreviations}

ANOVA, analysis of variance; BMI, body mass index; COPD, chronic obstructive pulmonary disease; COSYCONET, COPD and systemic consequences - comorbidities network; EQ-5D-3 L, EuroQol 5 dimensions questionnaire with 3 levels; FEV 1 , forced expiratory volume in 1 second; FVC, forced vital capacity; HRQL, health-related quality of life; KORA, Cooperative Health Research in the Augsburg Region; MCID, minimum clinically important difference; OLS, ordinary least squares, QALY, quality-adjusted life year; SD, standard deviation; SHIP, Study of Health in Pomerania, VAS, visual analog scale

\section{Funding}

This work was supported by the Competence Network Asthma and COPD (ASCONET). The COSYCONET COPD Cohort is funded by the German Federal Ministry of Education and Research (BMBF) with grant numbers 01GI0881, 01G10882 and by unrestricted grants from several pharmaceutical companies. The KORA research platform was initiated and financed by the Helmholtz Zentrum München - German Research Center for Environmental Health $(\mathrm{GmbH})$, which is funded by the German Federal Ministry of Education and Research and by the State of Bavaria. The KORA-Age project was supported by the German Federal Ministry of Education and Research (BMBF) with grant number $01 \mathrm{ET} 0713$.

The SHIP studies are part of the Community Medicine Research net of the University of Greifswald and were funded by grants from the German Federal Ministry of Education and Research (BMBF, grant numbers 01ZZ9603, 01ZZ0103, 01ZZ0701), the Ministry for Education, Research, and Cultural Affairs, and the Ministry for Social Affairs of the Federal State of Mecklenburg-West Pomerania.

\section{Authors' contributions}

MW, RL, and RH conceptualized the paper. MW, AKa, and RH performed the statistical analysis and MW, AKa, RL, and RH interpreted the data. MW and RH drafted the manuscript. RJ, AKa, AKo, and CV were involved in the coordination and the data acquisition of the COSYCONET study. JH, SK, HS, $A P, R L$, and $R H$ were involved in the coordination and the data acquisition of the KORA studies. RE, SB, and SG were involved in the coordination and the data acquisition of the SHIP studies. All authors critically reviewed each draft of the manuscript and approved the final manuscript.

\section{Competing interests}

$\mathrm{CV}$ reports personal fees outside the submitted work from the pharmaceutical companies Almirall, AstraZeneca, Boehringer Ingelheim, Chiesi, GlaxoSmithKline, Janssen, Mundipharma, Novartis, Takeda, Cipla, and grants and personal fees from Grifols. The authors declare that they have no competing interests.

\section{Ethics approval and consent to participate}

The COSYCONET study complies with the Declaration of Helsinki and Good Clinical Practice Guidelines and has been approved by the ethics committee of the medical faculty of the Philipps-Universität Marburg, the local ethics committees of the participating centers (a list of all participating study centers can be found here: http://www.asconet.net/html/cosyconet/studzent) and by the concerned data security authority (data security agency of the federal states of Hesse, Baden-Württemberg, Lower-Saxony, and Saarland). All cohort participants gave their written informed consent.

In KORA and SHIP, written informed consent was obtained from all participants, and the studies were approved by the Ethics Committee of the Bavarian Medical Association (KORA) and the Ethics Committee of the University of Greifswald (SHIP).

\section{Author details}

'Institute of Health Economics and Health Care Management, Helmholtz Zentrum München $(\mathrm{GmbH})$ - German Research Center for Environmental Health, Comprehensive Pneumology Center Munich (CPC-M), Member of the German Center for Lung Research (DZL), Ingolstädter Landstr. 1, 85764
Neuherberg, Germany. ${ }^{2}$ Institute and Outpatient Clinic for Occupational, Social and Environmental Medicine, Ludwig-Maximilians-Universität München, Ziemssenstr. 1, 80336 Munich, Germany. Institute for Biostatistics, Hannover Medical School, Carl-Neuberg-Str. 1, 30625 Hannover, Germany. ${ }^{4}$ Institute of Epidemiology I, Helmholtz Zentrum München (GmbH) - German Research Center for Environmental Health, Comprehensive Pneumology Center Munich (CPC-M), Member of the German Center for Lung Research (DZL), Ingolstädter Landstr. 1, 85764 Neuherberg, Germany. ${ }^{5}$ Institute of General Practice, University Hospital Klinikum rechts der Isar, Technische Universität München, Orleansstr. 47, 81667 Munich, Germany. ${ }^{6}$ Institute of Epidemiology II, Helmholtz Zentrum München (GmbH) - German Research Center for Environmental Health, Ingolstädter Landstr. 1, 85764 Neuherberg, Germany. ${ }^{7}$ Department of Internal Medicine B - Cardiology, Intensive Care, Pulmonary Medicine and Infectious Diseases, University Medicine Greifswald, 17475 Greifswald, Germany. ${ }^{8}$ Institute for Epidemiology and Preventive Medicine, University of Regensburg, Franz-Josef-Strauß-Allee 11, 93053 Regensburg, Germany. ${ }^{9}$ Institute for Community Medicine, University Medicine Greifswald, Walter-Rathenau-Str. 48, 17475 Greifswald, Germany ${ }^{10}$ Department of Medicine, Pulmonary and Critical Care Medicine, University Medical Center Giessen and Marburg, Philipps-University Marburg, Germany, Member of the German Center for Lung Research (DZL), Baldingerstraße, 35043 Marburg, Germany. ${ }^{11}$ Institute of Health Economics and Health Care Management, Munich Center of Health Sciences,

Ludwig-Maximilians-Universität München, Ludwigstr. 28 / RG, 80539 Munich, Germany.

Received: 23 March 2016 Accepted: 8 July 2016

Published online: 12 July 2016

\section{References}

1. World Health Organization. The top 10 causes of death, Fact sheet №310. http:// www.who.int/mediacentre/factsheets/fs310/en/. Accessed 27 Mar 2016.

2. Global Initiative for Chronic Obstructive Lung Disease (GOLD). Global Strategy for the Diagnosis, Management, and Prevention of Chronic Obstructive Pulmonary Disease (Update 2015). http://www.goldcopd.org/. Accessed 17 Mar 2016

3. Justine M, Tahirah F, Mohan V. Health-related quality of life, lung function and dyspnea rating in COPD patients. Monaldi Arch Chest Dis. 2013;79:116-20.

4. Rubinsztajn R, Przybylowski T, Maskey-Warzechowska M, Karwat K, Chazan R. Exacerbations of Chronic Obstructive Pulmonary Disease and Quality of Life of Patients. Adv Exp Med Biol. 2016;884:69-74.

5. Menn P, Weber N, Holle R. Health-related quality of life in patients with severe COPD hospitalized for exacerbations - comparing EQ-5D, SF-12 and SGRQ. Health Qual Life Outcomes. 2010;8:39.

6. Miravitlles M, Huerta A, Valle M, Garcia-Sidro P, Forne C, Crespo C, Lopez-Campos JL. Clinical variables impacting on the estimation of utilities in chronic obstructive pulmonary disease. Int J Chron Obstruct Pulmon Dis. 2015;10:367-77.

7. Miravitlles M, Ferrer M, Pont A, Zalacain R, Alvarez-Sala JL, Masa F, Verea H, Murio C, Ros F, Vidal R. Effect of exacerbations on quality of life in patients with chronic obstructive pulmonary disease: a 2 year follow up study. Thorax. 2004:59:387-95.

8. Huber MB, Wacker ME, Vogelmeier CF, Leidl R. Comorbid Influences on Generic Health-Related Quality of Life in COPD: A Systematic Review. PLOS ONE. 2015;10:e0132670.

9. Koskela J, Kilpelainen M, Kupiainen H, Mazur W, Sintonen H, Boezen M, Lindqvist A, Postma D, Laitinen T. Co-morbidities are the key nominators of the health related quality of life in mild and moderate COPD. BMC Pulm Med. 2014;14:102.

10. Baty F, Putora PM, Isenring B, Blum T, Brutsche M. Comorbidities and burden of COPD: a population based case-control study. PLoS ONE. 2013;8:e63285.

11. Decramer M, Rennard S, Troosters T, Mapel DW, Giardino N, Mannino D, Wouters E, Sethi S, Cooper CB. COPD as a lung disease with systemic consequences-clinical impact, mechanisms, and potential for early intervention. COPD. 2008;5:235-56.

12. Rutten-van Molken MP, Oostenbrink JB, Tashkin DP, Burkhart D, Monz BU. Does quality of life of COPD patients as measured by the generic EuroQol five-dimension questionnaire differentiate between COPD severity stages? Chest. 2006;130:1117-28. 
13. Kwon HY, Kim E. Factors contributing to quality of life in COPD patients in South Korea. Int J Chron Obstruct Pulmon Dis. 2016;11:103-9.

14. Hong JY, Kim SY, Chung KS, Kim EY, Jung JY, Park MS, Kang YA, Kim SK, Chang J, Kim YS. Factors associated with the quality of life of Korean COPD patients as measured by the EQ-5D. Qual Life Res. 2015;24:2549-58.

15. Jones PW. Health status measurement. In: Kolb M, Vogelmeier CF, editors. Outcomes in Clinical Trials. Lausanne: European Respiratory Society; 2013. p. 96-104.

16. Knies S, Evers SM, Candel MJ, Severens JL, Ament AJ. Utilities of the EQ-5D: transferable or not? Pharmacoeconomics. 2009;27:767-79.

17. Karch A, Vogelmeier C, Welte T, Bals R, Kauczor HU, Biederer J, Heinrich J, Schulz H, Gläser S, Holle R, et al. The German COPD cohort COSYCONET: Aims, methods and descriptive analysis of the study population at baseline. Respir Med. 2016;114:27-37.

18. Jorres RA, Welte T, Bals R, Koch A, Schnoor M, Vogelmeier C. Systemic manifestations and comorbidities in patients with chronic obstructive pulmonary disease (COPD) and their effect on clinical state and course of the disease-an overview of the cohort study COSYCONET. Dtsch Med Wochenschr. 2010;135:446-9.

19. Holle R, Happich M, Lowel H, Wichmann HE. KORA-a research platform for population based health research. Gesundheitswesen. 2005;67 Suppl 1:S19-25.

20. Peters A, Doring A, Ladwig KH, Meisinger C, Linkohr B, Autenrieth C, Baumeister SE, Behr J, Bergner A, Bickel $\mathrm{H}$, et al. Multimorbidity and successful aging: the population-based KORA-Age study. Z Gerontol Geriatr. 2011;44 Suppl 2:41-54.

21. Volzke H, Alte D, Schmidt CO, Radke D, Lorbeer R, Friedrich N, Aumann N, Lau K, Piontek M, Born G, et al. Cohort profile: the study of health in Pomerania. Int J Epidemiol. 2011:40:294-307.

22. Quanjer PH, Stanojevic S, Cole TJ, Baur X, Hall GL, Culver BH, Enright PL, Hankinson JL, Ip MSM, Zheng J, et al. Multi-ethnic reference values for spirometry for the 3-95-yr age range: the global lung function 2012 equations. Eur Respir J. 2012;40:1324-43.

23. Dolan P. Output measures and valuation of health. In: Drummond M, Alistair $\mathrm{M}$, editors. Economic evaluations in health care. Oxford: Oxford University Press; 2010. p. 46-67.

24. Greiner W, Claes C, Busschbach JJ, von der Schulenburg JM. Validating the EQ-5D with time trade off for the German population. Eur J Health Econ. 2005:6:124-30

25. Leidl R, Reitmeir P. A value set for the EQ-5D based on experienced health states: development and testing for the German population. Pharmacoeconomics. 2011;29:521-34.

26. Vogl M, Wenig CM, Leidl R, Pokhrel S. Smoking and health-related quality of life in English general population: implications for economic evaluations. BMC Public Health. 2012;12:203.

27. Soltoft F, Hammer M, Kragh N. The association of body mass index and health-related quality of life in the general population: data from the 2003 Health Survey of England. Qual Life Res. 2009;18:1293-9.

28. Hunger M, Baumert J, Holle R. Analysis of SF-6D index data: is beta regression appropriate? Value Health. 2011:14:759-67.

29. Martinez CH, Diaz AA, Parulekar AD, Rennard SI, Kanner RE, Hansel NN, Couper D, Holm KE, Hoth KF, Curtis JL, et al. Age-Related Differences in Health-Related Quality of Life in COPD: An Analysis of the COPDGene and SPIROMICS Cohorts. Chest. 2016:149(4):927-35.

30. Nici L, ZuWallack R. An official American Thoracic Society workshop report: the Integrated Care of The COPD Patient. Proc Am Thorac Soc. 2012:9:9-18.

31. Szende A, Oppe M, Devlin N. EQ-5D Value Sets: Inventory, Comparative Review and User Guide, vol. 2. Dordrecht: Springer Netherlands; 2007.

32. Weldam SWM, Schuurmans MJ, Liu R, Lammers J-WJ. Evaluation of Quality of Life instruments for use in COPD care and research: A systematic review. Int J Nurs Stud. 2013;50:688-707.

33. Petrillo J, van Nooten $F$, Jones $P$, Rutten-van MM. Utility estimation in chronic obstructive pulmonary disease: a preference for change? Pharmacoeconomics. 2011;29:917-32.

34. Wacker ME, Jörres RA, Karch A, Wilke S, Heinrich J, Karrasch S, Koch A, Schulz H, Watz H, Leidl R, Vogelmeier C, Holle R, COSYCONET-Consortium. Assessing health-related quality of life in COPD: comparing generic and disease-specific instruments with focus on comorbidities. BMC Pulm Med. 2016;16(1):70.

35. Luo N, Johnson J, Coons SJ. Using instrument-defined health state transitions to estimate minimally important differences for four preferencebased health-related quality of life instruments. Med Care. 2010;48:365-71.
36. Walters SJ, Brazier JE. Comparison of the minimally important difference for two health state utility measures: EQ-5D and SF-6D. Qual Life Res. 2005; 14:1523-32.

37. Stahl E, Lindberg A, Jansson S-A, Ronmark E, Svensson K, Andersson F, Lofdahl C-G, Lundback B. Health-related quality of life is related to COPD disease severity. Health Qual Life Outcomes. 2005;3:56.

38. Jones PW, Brusselle G, Dal Negro RW, Ferrer M, Kardos P, Levy ML, Perez T, Soler-Cataluna JJ, van der Molen T, Adamek L, Banik N. Health-related quality of life in patients by COPD severity within primary care in Europe. Respir Med. 2011;105:57-66.

39. Miravitlles M, Huerta A, Fernandez-Villar JA, Alcazar B, Villa G, Forne C, Cuesta M, Crespo C, Garcia-Rio F. Generic utilities in chronic obstructive pulmonary disease patients stratified according to different staging systems. Health Qual Life Outcomes. 2014;12:120.

40. Pickard AS, Wilke C, Jung E, Patel S, Stavem K, Lee TA. Use of a preference-based measure of health (EQ-5D) in COPD and asthma. Respir Med. 2008;102:519-36.

41. Einarson TR, Bereza BG, Nielsen TA, Hemels ME. Utilities for asthma and COPD according to category of severity: a comprehensive literature review. Jed Econ. 2015;18:550-63.

42. Leidl R, Schweikert B, Hahmann H, Steinacker JM, Reitmeir P. Assessing quality of life in a clinical study on heart rehabilitation: how well do value sets based on given or experienced health states reflect patients' valuations? Health Qual Life Outcomes. 2016;48:1.

\section{Submit your next manuscript to BioMed Central and we will help you at every step:}

- We accept pre-submission inquiries

- Our selector tool helps you to find the most relevant journal

- We provide round the clock customer support

- Convenient online submission

- Thorough peer review

- Inclusion in PubMed and all major indexing services

- Maximum visibility for your research

Submit your manuscript at www.biomedcentral.com/submit

) Biomed Central 